\title{
FULLY AUTOMATED MASONRY PLANT
}

\author{
Christian Hanser
}

\author{
Sommer Automatisierungstechnik (Austria) GmbH \\ A-1100 Vienna, Gudrunstraße 184/5/2 \\ email: somvie@atnet.at
}

\begin{abstract}
During the last years much effort was invested to develop an automated plant for prefabricating masonry elements. Partly automated systems were improved, but up to now none of them can be compared to the automation standards known from concrete precasting plants. In 1996 the first fully automated and highly flexible plant for different brick types started working near Ulm/Germany with the aim of reaching a production capacity of $300 \mathrm{~m}^{2}$ wall elements per shift. But technical and technological problems prohibited reaching the planned output in time. After takeover of the plant in 1997 the Sommer company was ordered to modernize and improve the plant and the software and install the originally expected capacity. By means of the meanwhile achieved results, the concepts, the machinery and workflow through the plant is explained and the critical sections are discussed. Last but not least the economic efficiency of the production line has been accomplished so that companies should be encouraged to invest in this missing link in prefabrication of houses.
\end{abstract}

\section{INTRODUCTION}

In contrast to concrete construction, in which prefabricated floor/ceiling and wall units have now become established as the technology most frequently used, masonry construction at the present time is still predominantly a domain of the craft operative, who is certainly equipped for his work with various auxiliaries but the activity of the bricklayer is basically still carried out in the traditional manner handed down over the centuries.

Here changes are going ahead, partly under pressure from changes of emphasis in the labor market and partly now possible due to the achievements of data processing and modern automation techniques. In the labor market it is increasingly difficult to obtain qualified personnel for the relatively heavy and exhausting activity of the bricklayer at reasonable cost. As is again apparent, the employment of a cheap workforce entails special problems and does not in fact represent a solution in the long term.

On the other hand it is indeed only a question of time before the process from the planning up to the completion of a building, which at present is still distributed among two to three dozen participants, beginning with the architect and extending to the last subcontractor, is more efficiently integrated into a whole by means of modern information technology. As in the productive branches of industry already for some time, an increase in producti- vity will also take place in the building industry as the answer to these redeployments in the market.

This increase will best be achieved by an orientation to site assembly construction: A large proportion of the building components will be manufactured at the works under constant and readily controllable conditions and then speedily erected on the building site. In the long term this means a displacement in the building cost structure in the direction of higher capital investment and a trend towards qualification of personnel for more highly qualified activities. It has been found from experience that this is where the strength lies of the high wage countries of the European Union.

In this field of technological and social constraints, the industrialized production of masonry is the missing link in prefabricating houses. Therefore the brick industry as well as building enterprises inspire and force developments in this field, to maintain the market for their traditional product at the one hand and to get the whole house made of prefabricated elements on the other [3].

\section{STATE OF ENGINEERING}

Based on the German Standard Specification DIN1053/4 numerous types of half-automatic plants have been developed in the last years as we can find in literature $[1,2]$. Most of them support the manual laying of bricks on a constant working height. Manipulation of stones and the complicated 


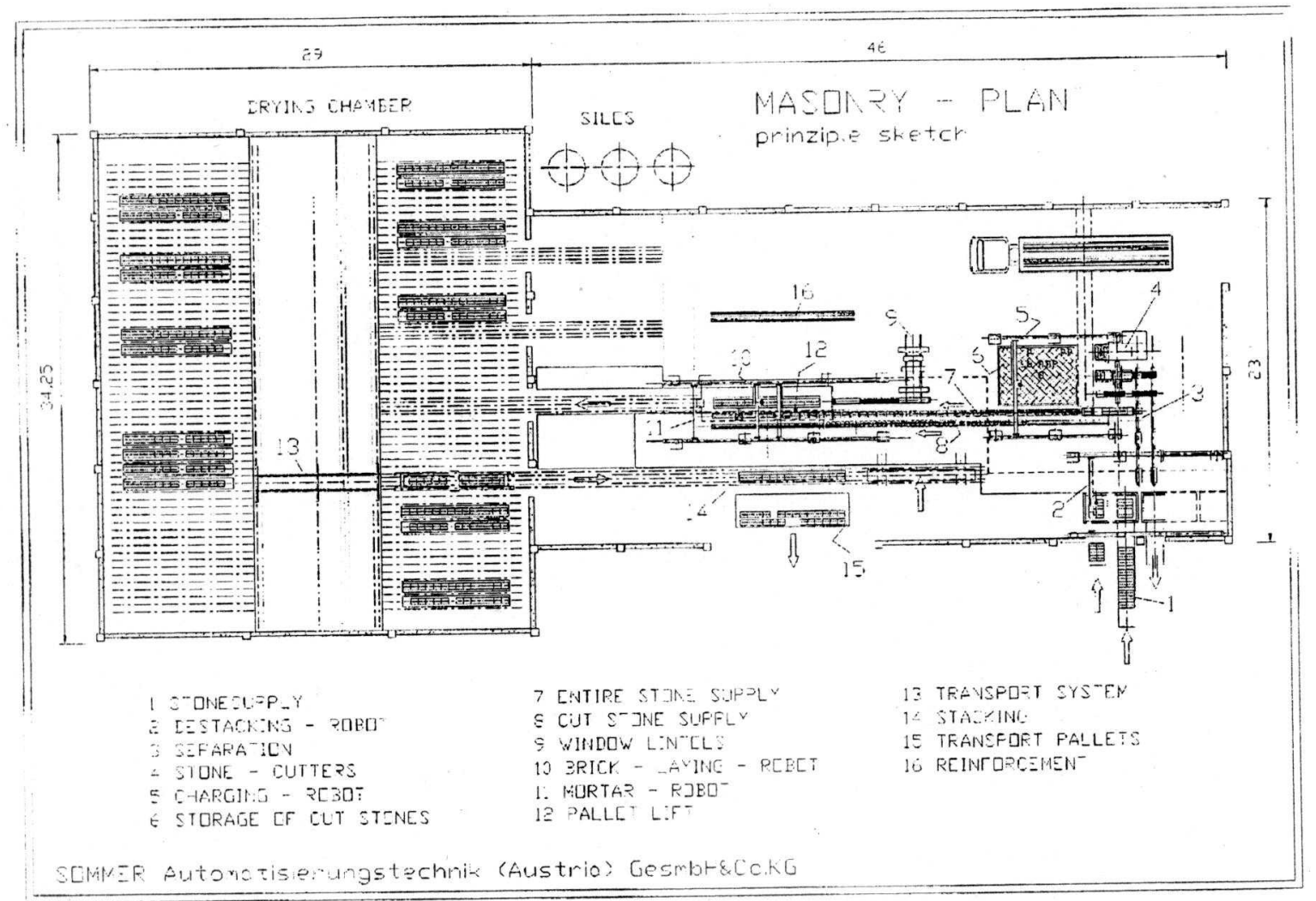

Figure 1: Arrangement of the machine components at the prototype-plant

cutting have still to be done by the worker.

The first flexible approach for a full automated plant for various stone-types and different wallthickness was built up in 1995 in Merklingen/Ulm, Germany[4-7]. The principle arrangement and workflow in the plant is shown in figures 1+2: Two individual brick types can be managed in parallel (this is very important when brick type changes) by an unloading gripper and the following cutter-system consisting of two stone saws. A special one, which is loaded by a robot to produce gable-bricks, edgebricks for windows or any other cuts which need the stone to be turned around anyway. And a second saw for simple cuts in length which is loaded with a conveyor belt. By two conveyor systems whole stone units and fitting stones are transported separately to the masonry robot system, where two independent robots move two bricks at each cycle to the growing wall after the mortar robot has put a layer of mortar on it. After each layer of bricks the pallet with the wall moves down until - after finishing the wall - the ground-floor is reached. There a pallet rotation system carries the wall to the drying chamber, optional refinement stations and after about 48 hours to the destacking station where the wall elements of the same order are grouped to delivry units on transporta-
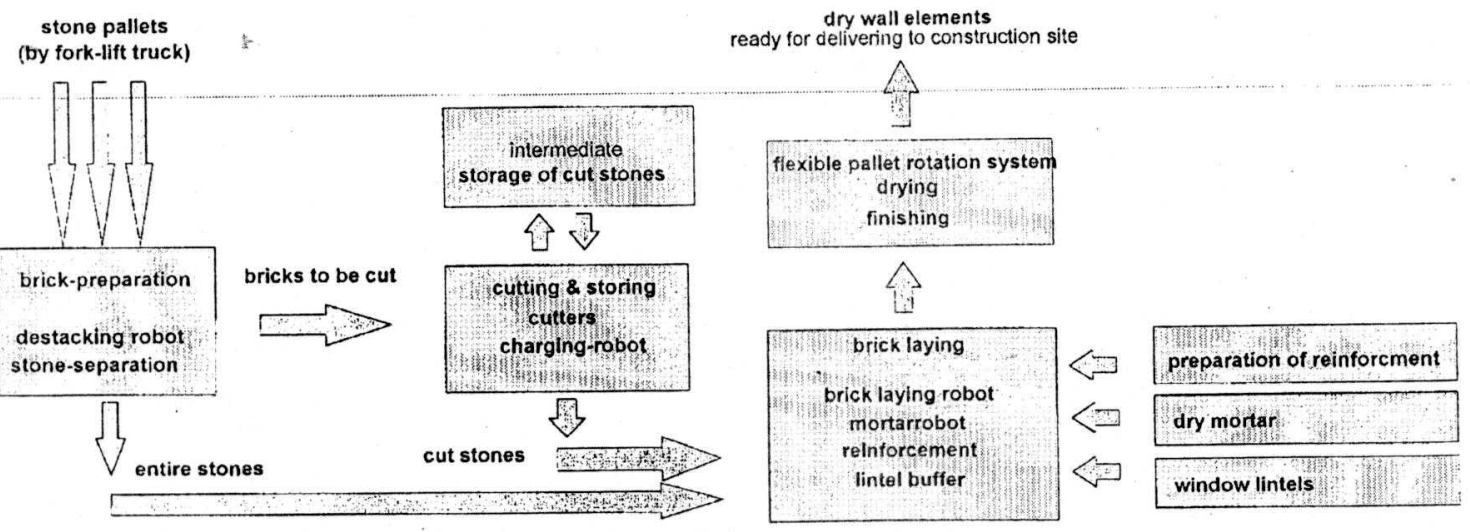

Figure 2: material-\& workflow through the plant 
tion pallets, which are moved to the resting-place and later by truck to the construction site. The empty production pallet is cleaned automatically and buffered for the next production cycle.

\section{THE OPTIMIZATION PROCESS}

At this prototype plant a lot of experience was collected during the last three years for optimizing the production-line in order to enlarge clement quality and throughput. This experience was the basis for our now described work during the last year.

\subsection{THE STONE CUTTER}

In the planning phase of the project the amount of cut stones was expected with a maximum of $30 \%$ [3]. In fact, it is about 50 percent on the average, which caused the cutting-machinery to be the absolute bottleneck of production. Therefore two approaches for optimization had to be done: First the planning algorithms in CAD must be improved with respect to minimize cut stones. In addition the pallet nesting algorithm on the master computer has to allocate critical elements on different production pallets, so that the amount of cut stones for each pallet keeps nearly constant. The second measure concerning the mechanics is to increase the performance of the cutting machines. This was a very difficult task, because the narrow room situation did not allow to integrate another cutter. So we decided to supply the sliding stone-support with a rotating platform for loading and unloading the saw by the robot. The average cycle time could be reduced to the half and the critical amount of cut stones could be raised up o 45 each pallet.

\subsection{BRICK QUALITY}

A negative experience was, that we never could trust a brick to be plane in shape, so that it has the tendency to move and turn around while being transported to the brick laying robots. In consequence many stones had to be realigned manually before the robot lays them onto the wall. If they wont be corrected in their position, the failure would be carried to the wall and cause quality deviations there, which cannot be accepted.

The quality of the raw bricks is the main theme in general. That starts with the amount of broken stones within a supplier pallet, which should be under $1 \%$ if we trust in the brick supplier, but ranges up to $15 \%$. The same situation is found if mechanic resistance is compared while transporting, gripping and cutting stones with equal attributes. Therefore we had to extend the plant with regard to realize, separate and collect broken stones and part of stones without manual interruption.

For aligning whole brick units a guide rail could

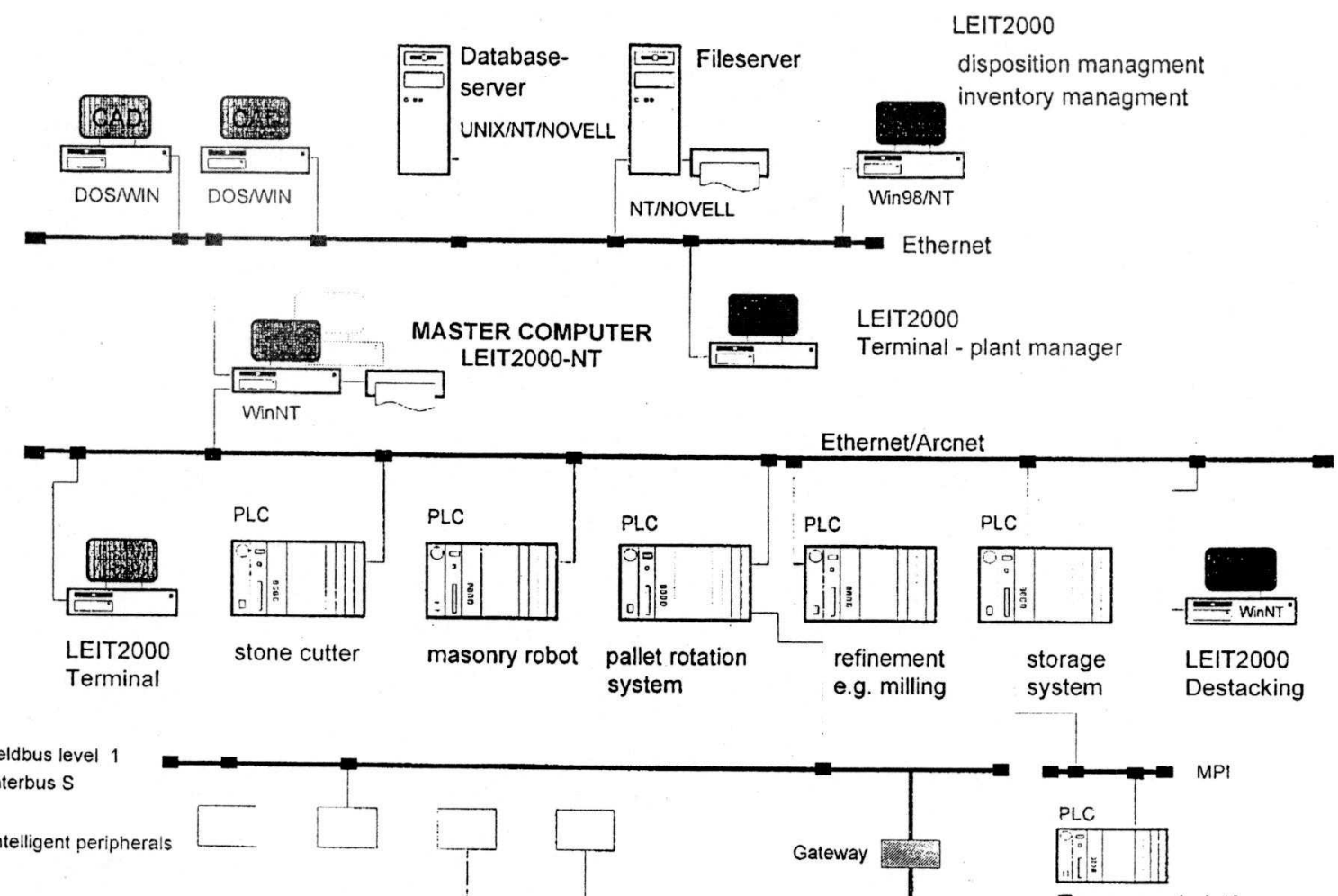

fieldbus leve! 2

Figure 3: Computer interconnection of the plant 
nearly all sections and tasks. Each part of the plant is reflected by a clearly defined program modules which are interconnected with a message system. Therefore the modules can be situated on different PLC's or PC's, but can nevertheless communicate with each other. In figure 3 a schematic view of the interconnection of the whole computer equipment is given.

\subsection{LOGISTIC REQUIREMENTS IN PRO- DUCTION}

This highly complex process needs an optimized logistic workflow in the plant, so that machines as rarely as possible have to wait for workers to interact an automatic process. Such tasks are still necessary as

- laying reinforcement bars onto the wall elements (3 times a pallet)

- roll out a separation foil under the first layer of bricks

- correcting failure situations caused by broken or deviated stones

Especially the last aspect requires efficient tools to analyze and correct failures. A visualization system of the plant state has to show the exact progress of a wall-element and answer for example the question: "Which stone is actually cut at the saw and which ones are now in the gripper of the bricklaying robot". Shortly, each process state must be made visible to the user.

Another important fact is the importance of an efficient transport logistic system to store elements at a resting place, separated from the drying chamber to achicve independence of displacements at the construction site. Weather influence and "traditional" planning requires an efficient product buffer for at least one week of production. For this means an automatic storage system was installed. A double platform system can pick up two types of transportation pallets $(6.000 \times 2.400$ $\mathrm{m}$ or $9.000 \times 1.500 \mathrm{~m})$, moves the pallet with the longitudinal platform to one of 15 storage rows (including the destacking station in the production hall) and then with the transversal platform to one of two resting areas on each side. The automatic function is guided by the master computer, where the deliverable pallets are chosen by number or order-description. First a dispatch note is printed, so that the truck-driver can request the right pallets from a terminal at the loading station. Empty pallets brought back from construction site can also automatically be stored from there.

\subsection{FEASIBILITY}

The discussed above and several other minor aspects have been optimized now in a second phase of investment, so that the plant could improve the throughput for about $50 \%$ and moved into an efficient economic region, which is the basis for further success of this new production line and the availability of prefabricated masonry in considerable volume. For the brick industry it is worth to promote prefabrication efforts, because modern wall elements of lightweight concrete (Liapor) took a tremendous growing development at the market. The following steps for further automation will increase the added value of the product "masonry panel"

- milling of conduit routing,

- installation of window and door frames,

- application of heat insulation and plaster

and will therefore let this technology be competitive almost against cheap labor from abroad.

To give an idea of the total investment for a plant with a similiar degree of automation a production area of about $2000 \mathrm{~m}^{2}$ is needed including the drying chamber and the amount of machine equipment can be quoted with 4-5 million DM. The whole plant can be implemented in 8-10 months until start of production.

\section{CONCLUSION}

An analysis of the construction market shows a definite trend at present towards rationalization of

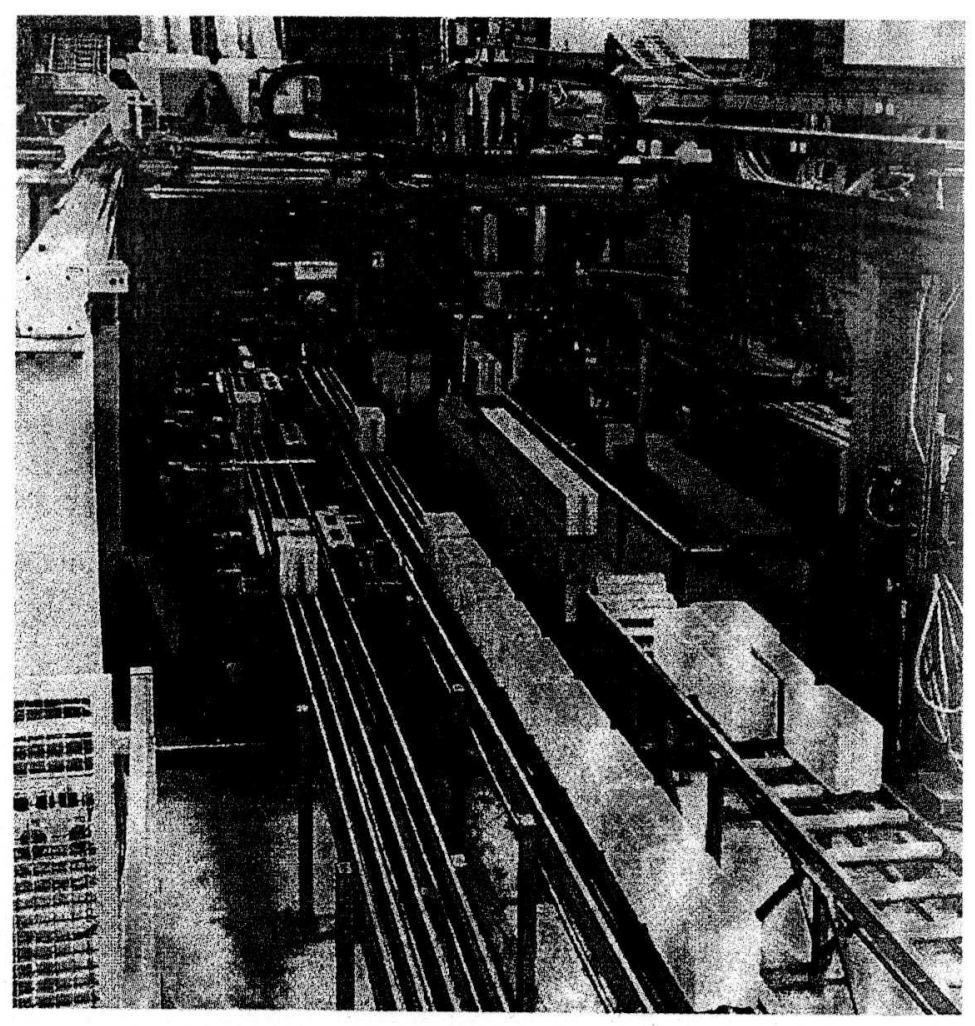

Figure 5: A general view of the bricklaying robot 
building, especially of housebuilding, which ultimately results in less expensive living space for the end consumer. This is obviously shown in the increasing sales figures for prefabricated houses of precast walls of cement-bonded lightweight aggregates such as expanded clay. To hold market shares the brick as a valuable building biological material has to join this rationalization trend. The huge effort, which is made in competition in this field by several companies especially in Southern Germany, shall be an indication for the growing importance of this theme. At a milestone of a long and expensive research \& development period, a plant is described, which is able to produce wall panels in every usual thickness with every usual brick type and in any shape as planned by the architect. And, quite necessary, cost effective with many additional advantages for the construction company such as independence of wether, shorter assembly time at the site and short construction time in general. The industrialized production in the factory building also quite naturally offers an opportunity of going a step further and of refining the wall elements produced and thus increasing the added value of the product.

\section{BIBLIOGRAPHY}

[1] Anliker, A.; Anliker, F.; Rothenbacher, K: Automation of Design and Construction of Single Family Houses of Brickwork. Proceedings of the 8th ISARC 1991 Stuttgart, S. 843-851.

[2] Klein, U.; Köhler, W.: Mauerwerksscheiben. Concrete Precasting Plant 2/1991, S. 74-80.

[3] Hanser, C.: Automation Concept for the Prefabrication of Masonry Elements. Dissertation TU-Vienna, Faculty of Mechanical Engineering 1994.

[4] Ainedter, D.; Hanser C. : Industrialized Production of Masonry. Brick and Tile Industry International 5/96, S. 284-287.

[5] Ainedter, D.; Hanser C. : Future is now. BMT Baumaschine+Bautechnik 5-6/1996, S. 25-28.

[6] Hanser, C.; Jörgl, H.P.: Automatisiertes Mauern. Elektronik International 7/1996.

[7] Ainedter, D.; Hanser C. : Vollautomatisiertes Mauern im Werk. Concrete Precasting Plant $12 / 1995$. 